Lexis Vol. XLIII (2) 2019: 339-367

\title{
Santa Rosa festejada: la exaltación del criollismo en Festiva Pompa de Juan Meléndez (1671)
}

\author{
Eva Valero Juan \\ Universidad de Alicante
}

\begin{abstract}
RESUMEN
El análisis de la relación de Juan Meléndez Festiva pompa, culto religioso, veneración reverente, fiesta, aclamación, y aplauso: a la feliz beatificación de la bienaventurada virgen Rosa de S. María (Lima, 1671) arroja luz sobre la función de las relaciones de fiestas como discursos que a lo largo del siglo XVII contribuyeron a la conformación de la identidad en el contexto virreinal. La utilización de Santa Rosa para la realización de una reivindicación americanista frente a España convierte esta relación en texto fundamental del criollismo a fines del siglo XVII. Al estudio del texto en este sentido, en conexión con otra obra del mismo autor, Tesoros verdaderos de las Indias (1681), se dedica el presente artículo.
\end{abstract}

Palabras clave: Meléndez, relación de fiestas, Festiva pompa, Perú

\section{ABSTRACT}

The analysis of the relationship of Juan Meléndez Festiva pompa, culto religioso, veneración reverente, fiesta, aclamación, y aplauso: a la feliz beatificación de la bienaventurada virgen Rosa de S. María (Lima, 1671) sheds light on the function of relationships of parties as speeches that throughout 
the seventeenth century contributed to the conformation of identity in the viceregal context. The use of Santa Rosa for the realization of an Americanist claim against Spain makes this relationship a fundamental text of the criollismo at the end of the seventeenth century. To the study of the text in this sense, and in connection with another work by the same author, Tesoros verdaderos de las Indias (1681), this article is dedicated.

Keywords: Meléndez, relationship of parties, Festiva pompa, Perú

\section{Introducción}

La riqueza literaria del Barroco americano se desarrolló en un contexto en el que los fastos tuvieron una relevancia muy significativa para comprender los modos con los que se edificó el mundo virreinal. El maridaje entre eclosión literaria y fastos llevó asociada la proliferación de las relaciones que daban cuenta pormenorizada de los mismos, dando lugar a un corpus textual abrumador a través del cual conocemos al detalle las características de esas celebraciones que eran de carácter religioso, político o cívico. Como apunta Teresa Ferrer, esta proliferación se explica por el hecho de que en la época de crisis que caracterizó la cultura barroca "la fiesta pública cobró un pleno sentido de propaganda de los poderes estatales o locales, civiles o eclesiásticos, y las relaciones, estrechamente vinculadas a ellas, florecieron sin tregua a lo largo y ancho del siglo XVII" (1993: 14).

Desde esta constatación conviene aclarar, a modo de introducción, la definición de esta tipología textual. De los estudios que abordan "la relación" como género, el libro de Dalmacio Rodríguez (1998), Texto y fiesta en la literatura novohispana (1650-1700), dedica un amplio capítulo a "La relación de fiestas como género histórico-literario", que supone una puesta al día muy completa sobre las perspectivas críticas con que se ha abordado hasta el momento este "género", sus aspectos ideológicos y formales, las características fundamentales para su definición, etc. Introduce el libro un prefacio escrito por José Pascual Buxó, en el que encontramos una 
explicación idónea como definición inicial de la tipología textual a la que nos referimos y enfrentamos:

[...] las relaciones de fiestas pueden combinar sin pecado las "ponderaciones" del historiador con los "encarecimientos del poeta" puesto que el ambiguo objeto de su discurso, por más que sea un acontecimiento "realizado" en un tiempo y espacio determinados y, por ende, un "acontecimiento" social del que puede darse un puntual informe, es ciertamente un espectáculo ficticio que se constituye como consecuencia de un elaborado programa alegórico cuyo referente inmediato es la puesta en escena de dicho espectáculo, fraguado - inventado y compuesto- con la participación de los recursos combinados de todas las artes. Ésta es la razón, como ha notado certeramente Dalmacio, de que en las relaciones de fiestas "concurran diferentes discursos generados en la fiesta misma" y cuyas afinidades formales - ser a un tiempo panegírico, descriptivo e historial- permiten establecer "con toda confianza un género", por más que tal género — por causa de la mixtura que hay en él, el de la relación de los festejos, la descripción de sus juegos y artificios y la transcripción de los textos poéticos vinculados a la fiesta- no haya sido canonizado ni por las preceptivas literarias ni por la historiografía (Pascual Buxó citado en Rodríguez 1998: 11).

En esta explicación la clarividencia de Pascual Buxó fija en pocas líneas las características y problemas fundamentales de estos textos y de su definición como género: el solapamiento de historia y literatura, tanto en lo referente a las formas como al contenido - un suceso histórico que al tiempo se configura como ficción escénica-; su esencia polifónica por la concurrencia de todas las artes en la escenificación que se relata; finalmente, la necesidad de su consideración como género por las afinidades que el conjunto de relaciones plantea - poseen una serie de tópicos literarios e históricos específicos-, a pesar de su exclusión histórica tanto del ámbito de la literatura como del de la historiografía. El problema se genera, por tanto, por la hibridación que los textos contienen, pero es precisamente en esa mixtura donde se sustenta su especificidad y, por tanto, su definición como género. 
Antonio Bonet Correa, en "La fiesta como práctica del poder", realiza un minucioso y revelador estudio de todos y cada uno de sus rasgos. Partiendo de la definición de la relación como relato de un suceso o acontecimiento que se pretende inmortalizar a través de la escritura - y que, por tanto, combina la tarea de narrar con la de informar-, y distinguiendo las relaciones impresas —las más numerosas - de las manuscritas, el crítico aporta seguidamente una descripción de las relaciones, desde un punto de vista formal, que merece recordarse como marco del que partimos para establecer luego cierta discrepancia:

Obras de literatura laudatoria, en prosa unas y otras en verso y salvo raras excepciones de autor de talla, al igual que los centones, las loas y los panegíricos, sus volúmenes forman un centón de apretados conceptos, expresados con fórmulas estereotipadas. Con sus latiguillos obligados pertenecen a un género muy caracterizado de hiperbólicas y elípticas frases, cuya lectura resulta cansina por la monótona y pesada repetición, sin proporcionar sorpresas. Quien ha leído una relación puede decir que ha leído todas (1983: 49).

Si bien podemos convenir con esta opinión en lo que atañe a la escasa brillantez literaria de este género, constreñido en la rigidez de fórmulas fijas, repetitivas y estereotipadas, y monótono en la descripción minuciosa de todo detalle de la celebración relatada, de esta constatación que atañe a lo formal no se puede inferir una falta de sorpresa en los textos que, en las líneas citadas, parece afectar también a su contenido. Como veremos, el análisis de Festiva pompa aporta tal variedad de claves para la interpretación de la historia social que concierne a la escenificación, que el juicio generalizador de Bonet Correa tan solo puede comprenderse si nos referimos al estilo y las características formales. Por ello, es importante alertar, como hace Dalmacio Rodríguez (1998: 122), sobre el hecho de que una vez trazadas las líneas generales del género por estos autores, es tarea inaplazable profundizar en el contenido de los textos de manera individualizada, para su revalorización como documentos que contienen un potencial de significaciones históricas de gran 
valor socio-cultural. Tal es el objetivo del presente artículo. En este sentido, Francisco López Estrada (1982) alerta sobre el hecho de que la escasa valoración de estos textos se ha podido derivar de su no reconocimiento como textos literarios y de su tratamiento como piezas con meros datos históricos y, por tanto, de interés circunstancial. Superada esta generalización, cuya carga peyorativa había supuesto la exclusión académica de este inmenso corpus textual, la crítica de las últimas décadas dedicada a su estudio ha partido de la necesidad de penetrar en estos textos en busca de significaciones y mensajes que están en la base de la intencionalidad del autor, tratando de tener en cuenta las circunstancias que enmarcan y explican la época en la que se producen. ${ }^{1}$ Dicha profundización temática tan solo puede abordarse de manera individualizada, por lo que propongo un modelo de análisis a través de Festiva pompa de Meléndez.

Otras líneas generales sobre las "relaciones de sucesos" se centran en la evidencia de no constituir un género literario en el sentido clásico del término, dada esa hibridez resultante de la fusión de historia y literatura, a las que se suman todas las artes —-música, pintura, arquitectura...- puestas al servicio del fasto relatado. Partiendo de esta evidencia hay que constatar una segunda reflexión, y es que la relación es producto, continuación y conclusión de la fiesta. En este sentido es importante destacar que sus páginas, como apunta Bonet Correa, "encierran la pretensión de ser por sí mismas un monumento más, una arquitectura literaria levantada para la sempiterna memoria de tan señalado acontecimiento del que siempre el sujeto era el príncipe o monarca" (1983: 51). Es decir, la relación de un suceso es, a fin de cuentas, el equivalente de aquellas arquitecturas efímeras características del Barroco hispánico que se levantaban para los fastos, puesto que, como advierte López Estrada, solía ser "una publicación fugaz como la misma Fiesta que pronto pasa y se

\footnotetext{
Un planteamiento metodológico para estudiar este tipo de documentos vendría desde la Microhistoria, con su reducción de la escala de observación para, a través de indicios, de la relación de lo particular con lo social y del relato de un acontecimiento, abrir la perspectiva al contexto social y cultural que determina el episodio. Sobre la Microhistoria siguen siendo esenciales Ginzburg (1981); Cipolla (1984); y Darnton (1987).
} 
olvida. No hay sucesivas ediciones y se trata de libros predispuestos a perderse, pues sólo los conservan los coleccionistas del lugar y los historiadores como fuente de datos curiosos de menor cuantía. De ahí procede su rareza bibliográfica” (1982: 302).

Sin embargo, a pesar de este destino fugaz predeterminado por la esencia de estos textos, el poder de perdurabilidad de la letra escrita hizo que en muchos casos sobrevivieran, de modo que aquellas arquitecturas efímeras que hoy conocemos a través de sus descripciones textuales, de no ser por la relación hubieran desaparecido, no solo de la esfera de su realidad histórica, sino también de la memoria y de la historia colectiva. Sobre esta cuestión, resulta interesante recordar las palabras de Octavio Paz en las que abunda en la esencia efímera de la fiesta barroca: "Estética de lujo, arte de la disipación. El barroco inventó formas pletóricas y henchidas que, en pleno frenesí vital, desfallecen atraídas por el vacío. La fiesta barroca es un ars moriendi [...] el dinamismo, la sensualidad y el movimiento de la fiesta culminan en un mausoleo, es decir, en un monumento - sea de piedra o de palabras" (1995: 203). En definitiva, el monumento de palabras que es la relación nos permite conocer ese ars moriendi que de otro modo habría desaparecido en su propia finitud, y si podemos hablar de "monumento" para referirnos a estos textos, lógicamente no es por la calidad literaria de los mismos, sino por la idea de perdurabilidad del acto social que tal imagen posibilita y transmite.

En el virreinato del Perú, una compilación de relaciones de fiestas (anónimas o de autor, impresas o manuscritas) resulta intensamente reveladora de la centralidad que las fiestas tuvieron desde época muy temprana para los conquistadores, colonos y mandatarios posteriores, y abre un campo de estudio fundamental para seguir profundizando en el Barroco peruano. De la compilación se deduce que las más abundantes corresponden a las cortesanas ( $c f$. Ramos Sosa 1992). En este sentido, hay que tener muy presente la diferencia entre las fiestas de carácter religioso y las fiestas de carácter repentino. Las primeras se sucedían cada año en la misma fecha, con una rígida organización cuyo fin era el adoctrinamiento 
de los fieles en la moral y el dogma católico; las segundas solo las podían celebrar quienes tenían autoridad de príncipe y se organizaban repentinamente, sin obedecer a ninguna periodicidad, sino a la celebración de acontecimientos vinculados con la corona, así como con la iglesia — cuando se trataba de eventos extraordinarios, beatificaciones, canonizaciones, etc.-. Ahora bien, estas últimas nunca eran totalmente profanas, pues el componente religioso siempre tenía su lugar cuando lo lúdico se enseñoreaba de la ciudad. Eran, además, la expresión más clara de la intervención directa del soberano, quien integraba al pueblo como súbdito, y cuya función era, por tanto, la de alabanza a la autoridad, la cual, en el ámbito hispanoamericano, tenía a sus delegados - las autoridades indianas - como directores de tramoya. Por último, hay que recordar que se organizaban a través de una gran representación escénica, siendo el grupo social mandatario el actor principal, integrado por los peninsulares con cargos de responsabilidad y por los criollos que dominaban los cabildos eclesiásticos y seculares: "como no existía la posibilidad de contar con la presencia física del soberano para conmemorar tales eventos, se ideó un procedimiento que paliara en parte dicha dificultad. Las autoridades indianas ocuparían su lugar y desempeñarían el papel de coprotagonistas en las festividades, como representantes de la Corona en Indias" (López Cantos 1992: 28).

Entre las relaciones cortesanas destacan las destinadas al recibimiento de nuevos virreyes o la proclamación de nuevos reyes de España. Así por ejemplo las siguientes: Relación de las fiestas que se celebraron en la corte de Pausa por la nueva de proveimiento de virrey en la persona del Marqués de Montesclaros (Anónimo 1607); Relación de la Cabalgata Real, y solemne aclamación, que el día 8 de enero de este año de 1702 bizo la muy noble y leal cindad del Cuzco, celebrando la jura del Católico Rey D. Felipe V. deste nombre, Nuestro Señor, Monarca de las Españas, y Emperador de las Indias (1702); Relación de la entrada publica que bizo en Lima, Capital del Perú el día tres de Diciembre de este año de 1776 el Exmo. Señor Don Manuel Guirior Caballero del Orden de San 
Juan Teniente General de la Real Armada, Virrey Capitán General del Reyno del Perú y Chile (1776); Descripción de las Reales Fiestas que por exaltación del Señor Don Carlos IV al Trono de España y de días celebró la muy noble ciudad de Lima (1790); Relación sucinta de las fiestas celebradas en la cindad de Nuestra Señora de la Paz, en el Perú, a costa del regidor de ella Don Tadeo Diez de Medina, con motivo de la exaltación al trono del Señor Rey Don Carlos IV (1791), etc.

Otras relaciones describen los festejos por el nacimiento de príncipes: Fiestas que celebró la Ciudad de los Reyes del Pirú, al nacimiento del Serenísimo Príncipe Don Baltasar Carlos de Austria nuestro señor (por Rodrigo de Carvajal y Robles 1632); o la Relación de las fiestas reales, que esta muy noble y leal Ciudad de los Reyes celebró este año de 1659 al nacimiento feliz de nuestro Príncipe y señor natural C. Felipe Próspero, Principe de las Españas y deste nuevo Mundo (por Diego de Ojeda 1659), ${ }^{2}$ entre otras. Y dentro de este grupo encontramos también relatos de festejos para alabanza de reyes, virreyes y personajes ilustres, como por ejemplo: Aclamación y pendones que levantó la muy noble y coronada Ciudad de los Reyes, por el católico y augustísimo rey D. Carlos II (1666); Fiestas de los Naturales de esta ciudad de Lima y sus contornos en celebridad de la exaltación al Trono de S. M. el Señor don Carlos III Nuestro Señor (1760); Debidos aplausos, y célebres funciones que esta M. N. y L. Ciudad de Lima hace al recibimiento del Exmo. Señor Fray Don Francisco Gil de Taboada Lemos y Villamarín del Consejo de S. Mag (1791), etc.

En cuanto a las fiestas religiosas, las más abundantes están dedicadas a festejar beatificaciones y canonizaciones. La investigación sobre las mismas arroja los siguientes títulos, entre los más destacados: Relación de las fiestas que en la ciudad de Lima se bicieron por la beatificación del bienaventurado Padre Ignacio de Loyola, fundador de la Religión de la Compañia de Jesús (1610) (festejo celebrado también en Cuzco en el mismo año); Festiva pompa, culto

2 Sobre los festejos de nacimientos de príncipes, véase Ramos Sosa (1997). 
religioso, veneración reverente, fiesta, aclamación, y aplauso: a la feliz beatificación de la bienaventurada virgen Rosa de S. Maria (1671); Breve Relación, del aplauso con que esta Ciudad de Lima ba celebrado la llegada de las Bullas Originales de su Arzobispo el Illmo. Señor Doctor Don Joseph Antonio de Cevallos del Cavallero (1743). A las que cabe añadir los autos de fe y las exequias por la muerte de soberanos o personajes ilustres, como por ejemplo esta Relación del Auto de Fe celebrado por el Sagrado Tribunal del Santo Oficio de la Inquisición de estos Reynos. En la muy noble y Leal Ciudad De Lima, Capital de esta América Austral, en el día 12 de Julio del año de 1733, escrita por Pedro de Peralta y Barnuevo (1733).

\section{Juan Meléndez y Rosa de Lima}

Más allá de dar prolija noticia de los sucesos acaecidos en las ciudades y pueblos de España y América durante los siglos de la Colonia, todos estos textos contribuyen a la conformación de la identidad de dichos pueblos. En este sentido, destaca sobremanera la relación de fray Juan Meléndez objeto del presente estudio: Festiva pompa, culto religioso, veneración reverente, fiesta, aclamación, y aplauso: a la feliz beatificación de la bienaventurada virgen Rosa de S. María (Lima, 1671). Conocido por ser el autor de Tesoros verdaderos de las Indias (1681), Meléndez estuvo a cargo de la relación de fiestas con que el Cabildo de Lima, el virrey y la Orden de Santo Domingo, así como diversas instancias, celebraron la beatificación de Rosa de Lima. El volumen —relato de 121 páginas— contiene la relación de los fastos así como, al final, diversas composiciones poéticas en honor de la entonces primera beata de América, los mismos que formaron parte de las diversas celebraciones. Asimismo, incluye los poemas en distintos metros y estilos del certamen poético organizado por esta orden de predicadores. Dichos poemas, impresos en grandes pliegos, fueron recopilados por Meléndez como colofón de su extensa relación.

Pero antes de entrar en el análisis del texto es necesario reparar en el autor, fray Juan Meléndez, en tanto que el perfil ideológico 
de su figura se desarrolla en la reivindicación criollista que vamos a encontrar en Festiva Pompa. En Lima fundida. Épica y nación criolla en el Perú (2016), José Antonio Mazzotti dedica un capítulo al autor, especialmente revelador para comprender la dimensión mitificadora de Lima y sus habitantes presente en el texto. Titulado "Meléndez y la superioridad moral criolla” (2016: 155-158), en sus páginas Mazzotti delinea la dimensión de este dominico criollo nacido en Lima, perteneciente a la alta jerarquía de la iglesia, que "esgrimió una de las más elocuentes defensas de los criollos y de la superioridad material y espiritual del Nuevo Mundo en sus Tesoros verdaderos de las Indias (1681)" (2016: 155). Los objetivos de esta obra, trazados por Mazzotti, coinciden, como veremos, con uno de los que sin duda persigue en Festiva Pompa: la exaltación de la religiosidad de Lima y de sus habitantes blancos, que desde el punto de vista de Meléndez serían intelectualmente superiores en el conjunto del imperio español. Es más, el segundo volumen de Tesoros coincide con la relación en la temática, pues está dedicado a la vida ejemplar de Rosa de Lima.

En tanto que esta obra apareció diez años después de Festiva Pompa, bien podemos trazar un claro hilo conductor del proyecto ideológico de Meléndez, pues las ideas de esta relación de fiesta tendrían después un desarrollo mayor, transcurrida una década, en esta obra (Tesoros) que Mazzotti sitúa con acierto en los contornos de la famosa "disputa del Nuevo Mundo" dieciochesca (tal y como la denominó Antonello Gerbi en su clásico La disputa del Nuevo Mundo: historia de una polémica, 1750-1900, de 1993). Como vamos a ver, Festiva Pompa constata esa vinculación de Meléndez con los términos en que se desarrolló la conocida "disputa", por lo que podemos afirmar que este texto se erige en antecedente de la misma, en 1671. Mazzotti desarrolla el vínculo con la "disputa" en un doble plano de ida y vuelta entre Europa y América:

La degradación ontológica de un buen grupo de españoles a un nivel subhumano recuerda el mismo lenguaje utilizado por autores europeos para referirse al 'otro' cultural hallado en el Nuevo Mundo. Ya en el siglo xviii, la 'disputa del Nuevo Mundo', como acertadamente la llamara don Antonello Gerbi, repetiría algunos de los mismos 
términos de desprecio bajo la pluma del conde de Buffon y de Corneille de Pauw. Si los súbditos de la Corona nacidos en Indias eran concebidos y tratados como bárbaros en potencia y por lo tanto naturalmente inferiores [...] era lógico para un alto cuadro de la intelectualidad criolla y muchos otros de sus coterráneos apropiarse de ese discurso, invertido y devolverlo envuelto en un texto cargado de ejemplos de la autoproclamada grandeza espiritual (2016: 156).

Con estas ideas iniciales, nos situamos en el marco ideológico necesario para adentrarnos en la relación de fiestas de Meléndez. El texto invoca a la mujer beatificada como una hija espiritual de la religión de Santo Domingo y, sobre todo, como fruto de América. Recordemos que Rosa de Lima fue la primera nacida en América beatificada, el 12 de febrero de 1668, primera santa de las Indias —una santa criolla-. Al año siguiente, en 1669, sería nombrada Patrona de Lima y del reino del Perú; en 1670, de las Indias y Filipinas; y sería canonizada en $1671 .^{3}$ La utilización de su figura por parte de Meléndez para la realización de una reivindicación americanista frente a España convierte esta relación en un texto fundamental para el análisis de la evolución del criollismo a fines del siglo XVII. Pero también para constatar, una vez más, la funcionalidad de las relaciones de fiestas en la transmisión de una propaganda ideológica. Recordemos, en este sentido, los planteamientos de José Antonio Maravall en su libro clásico La cultura del Barroco: "Las fiestas van ligadas, como manifestación característica, a la sociedad barroca, porque responden a las circunstancias de la misma. Son, como todos los productos de la cultura barroca, un instrumento, un arma incluso, de carácter político. Lo advirtieron reyes y ministros que gastaban en fiestas lo que no podían” (1996: 494).

También Antonio Bonet Correa, en su trabajo significativamente titulado "La fiesta barroca como práctica del poder" (43-84), desarrolló este planteamiento reiterado en los estudios sobre esta tipología textual:

Desde la década de 1990 se han sucedido los estudios sobre la figura de Rosa de Lima. Vid. Millones 1993, Hampe 1998, Mujica Pinilla 2005, Millar Carvacho 2003, Folquer 2010 y Báez 2012. 
El regocijo popular, la alegría y risa en común, la locura colectiva fue como una válvula de escape que de vez en vez y a su debido tiempo se abría para así mantener el equilibrio y la conexión entre las clases, a fin de que el edificio "bien construido" del antiguo régimen no sufriese resquebrajaduras amenazadoras de su estabilidad. También fue un eficiente lenitivo que hacía soportable el trabajo y penalidades de los días laborables (1983: 45).

3. Sobre los festejos dedicados a Santa Rosa

Para el estudio de la Festiva Pompa, partimos de los trabajos que en los últimos años han proliferado sobre los fastos por la beatificación de Rosa de Lima: Arias Cuba 2013, Farré 2012, Pérez 2015, Zugasti 2013 (unas décadas antes Vargas Lugo 1983 y 1988). Sobre el proceso de beatificación de Santa Rosa da pormenorizada noticia e información Miguel Zugasti en su trabajo "Santa Rosa de Lima, una santa del pueblo con sus fiestas y comedias para el pueblo" (2013). Según Zugasti, "era una demostración palpable del arraigo de la cristiandad en el Nuevo Mundo y, sobre todo, del orgullo criollo" (2013: 4). En su trabajo, el crítico recorre las comedias dedicadas a Santa Rosa que tuvieron lugar en Lima, México, Manila, Madrid y Sevilla. Y compila en apéndice final una relación de impresos antiguos sobre Santa Rosa (bulas apostólicas, sermones, hagiografías, relaciones de festejos, certámenes poéticos...) que, siguiendo un orden cronológico, resulta especialmente útil para la conformación de este corpus textual: desde la primera hagiografía en 1659, de fray Juan de Vargas Machuca, "hasta los más lejanos ecos de su canonización emitidos en Manila en 1677” (Zugasti 2013: 17).

En lo relativo a los fastos celebrados en Lima en honor de la beatificación, tenemos tres textos: el que me ocupa en el presente estudio, el de León Pinelo (Celebridad y fiestas, Lima, 1670) y una relación escrita por Gonzalo Andrés de Meneses y Arce, Ilustración de la Rosa del Perú (Lima, 1670). Las tres aprovechan el motivo de la beatificación para el enaltecimiento de Lima y de la patria criolla, elegida por Dios para que allí naciera Santa Rosa, de modo que Lima aparece como centro de la civilización y punto neurálgico de 
la cristiandad. En definitiva, Lima se construye como espacio privilegiado dentro del imperio, idea que la canonización final de Santa Rosa sellaría.

Por su parte, Ybeth Arias Cuba, en su trabajo "En torno a las fiestas de beatificación de la Rosa indiana (1668-1671)", estudia las fiestas por esta beatificación celebradas en Lima (la citada de Diego de León Pinelo de 1670 y la de fray Juan Meléndez), México (de Antonio Morales y Pastrana, 1671) y Madrid (de Nicolás Matías del Campo de la Rinaga, 1668 y de Fray Jacinto de Parra, 1670). Este trabajo analiza la trayectoria de los dominicos en las Indias, estableciendo el vínculo entre la beatificación y el enaltecimiento de la orden dominica, ${ }^{4}$ así como la utilización de la beatificación para la alabanza de Lima y Perú como patria de la primera beata indiana, sobre la que abundo a continuación en el análisis de la Festiva Pompa. Interesa este estudio especialmente por su establecimiento del contraste entre las fiestas acaecidas en Lima y México y las de Madrid, en tanto que las americanas insisten en la idea de patria criolla, en el orgullo derivado y en la condición de 'natural de la tierra' de Rosa; por el contrario, la de Madrid subraya la condición de Rosa como vasalla de la monarquía.

Asimismo, Mirzam C. Pérez incide en esta perspectiva en "Fomentando la identidad institucional dominicana en tres relaciones de fiestas para la beatificación de Santa Rosa de Lima", un estudio en el que compara tres relaciones por la beatificación celebradas en Granada, ${ }^{5}$ Cádiz $^{6}$ y Lima. En esta comparación, la autora recorre ejes vertebrales del texto de Meléndez: su inscrip-

\footnotetext{
4 "Rosa de Santa María tuvo doce confesores y un director espiritual. Siete fueron dominicos (Pedro Loayza, Sebastián de Lorenzana, Alonso Velázquez, Francisco de Madrid, Juan Pérez, Bartolomé de Ayala Y Luis de Bilbao), cinco jesuitas (Juan de Villalobos, Diego Peñalosa, Antonio de Vega y los 'Siervos de Dios' Diego Martínez y Juan Sebastián de la Parra)" (Iwasaki 2018: 232).

5 Ver Relación breve de las fiestas que el real convento de Santa Cruz de Granada dispuso y hizo en la beatificación de la venerable y Esclarecida Virgen la Bienaventurada Rosa de Santa María, Granada (Bolíbar 1668).

6 Ver Relación compendiosa y diaria de las fiestas que se celebraron por onze días en el Convento del Señor de Santo Domingo y el Rosario, de la ciudad de Cádiz, a la esclarecida y bienaventurada Rosa de Santa María... Cádiz (Anónimo 1669).
} 
ción en la tradición de las laudes civitatum, en tanto que "alaba las contribuciones estéticas y arquitectónicas de los edificios dominicanos pero lo hace añadiendo tres largos capítulos que describen los espacios, imágenes, y lujos de estos lugares” (Pérez 2015: 128); la alabanza de las autoridades americanas: "de la misma manera en que la relación de Cádiz menciona el uso de retratos reales para representar la presencia y aprobación monárquica, el texto de Lima menciona la presencia, participación, y regalos del Virrey y la Virreina de Lima en los eventos planeados, evidencia del profundo compromiso de las autoridades locales" (Pérez 2015: 128); la exhaustividad de la extensa información recopilada, que aporta documentación suplementaria para mayor gloria de la beata: "una transcripción de la bula papal de beatificación, una carta de la Reina Mariana enviada para la ocasión, la biografía de la vida y milagros atribuidos a Rosa, y una colección de poemas laudatorios complementan y contextualizan la relación" (Pérez 2015: 128); por último, el tema sobre el que cabe añadir nuevos fragmentos, en lo que atañe al carácter americano de Santa Rosa: "muy de notar es que mientras los textos de Granada y Cádiz afirman que Rosa es el producto del éxito dominicano en la iniciativa colonial, el texto de Lima hace alarde de la mujer beatificada como una 'hija spiritual de la religión de Santo Domingo'” (Pérez 2015: 128) y, sobre todo, como fruto de las Américas.

Por último, Judith Farré ha estudiado una temática fundamental para abordar la Festiva Pompa: "Poéticas del espacio en las relaciones de festejos novohispanos: la beatificación de Santa Rosa de Lima”; un trabajo en el que analiza la cuestión espacial en textos en los que, al igual que los peruanos, el culto a la santa será "germen de la posterior utilización sociopolítica del imaginario rosariano" (2012: 286). Este artículo resulta especialmente significativo en lo referente al análisis del citado texto Solemne, plausible, festiva pompa de Antonio de Morales Pastrana (1671), pues permite observar dicho imaginario en el de Meléndez y comprobar las coincidencias entre ambos textos, por ejemplo, en la identificación de Santa Rosa con la Aurora, "aspecto que —escribe Farré-, según la preceptiva clásica, permite pensar en la nueva santa americana 
como motivo de esperanza y fecundidad" (2012: 293). En la Festiva pompa, dicha identificación se formula en estos términos:

Nos pues pierde la Rosa Peruana por auer nacido al Mundo en campo, que en otro tiempo fue teatro de la noche, y nublado del Gentilismo de esta plaga Occidental; antes si (como lo suaue de la Rosa en lo duro de las espinas) campea mas su luz en las tinieblas como rozagante Aurora: que si de esta conto el Nantuano Virgilio, tenia rosados los cabellos: Aurea fulgebat roseis aurora capillis (Meléndez 1671: fol. 104).

Asimismo, Farré señala otro motivo recurrente, la metáfora que equipara flores y estrellas presente en la continuación del fragmento precedente - "por Rosa simboliza con ella su hermosura, cuyas luzes, como las del Alua fueron en crecimiento cada dia, brillando en heroicas virtudes, de virginal pureza, de ardiente caridad, Reyna de todas, como la Rosa fragante de las flores" (Meléndez 1671: fol. 104)-, entre otros motivos que configuran un programa alegórico "que supone reconocer la fertilidad del suelo, es decir, la espiritualidad americana, al producir flores de fragancia, como Santa Rosa de Lima" (Farré 2012: 297). En suma, concluye con acierto Farré, se trata del "establecimiento de este modelo de santidad criollo", que "pasa por reproducir los motivos iconográficos fundamentales que muestran la figura de la santa como primera flor del jardín dominico en América” (2012: 299).

\section{La reivindicación americanista}

Esta reivindicación americanista está presente a lo largo de todo el texto de Meléndez. Pero veamos primero, de forma sintética, su contenido, comenzando por señalar que la dedicatoria está dirigida "a la catolica y cesarea magestad de la Reina N.S. Doña Mariana de Austria, emperatriz de dos mundos" (1671: fol. 17). La extensa relación cuenta con todo pormenor la llegada de la noticia de esta beatificación a Lima en 1668, para pasar luego a dar noticia, no menos detallada, de la fiesta celebrada en Lima, en la que cabe destacar la participación activa y plena de "los pobres indios" agasajando 
a "la Rosa": "Ni en la miseria de los pobres indios falto agasajo, que hacer a su diuina Paysana la Rosa [...] fabricaron a su triunfo hermosos triunfales arcos” (1671: fol. 27). Después encontramos el sermón de la celebración de la bula de su beatificación ${ }^{7}$ y el relato de las procesiones, los cantos en las vísperas, el certamen poético de ocho alumnos y procesión por el claustro de la universidad, con cuatro máquinas de fuego y faroles pendientes de la torre en la tarde del quinto día a cargo de la Universidad de San Marcos. No faltan tampoco en esta fiesta religiosa los mismos elementos de la fiesta cortesana: fuegos en la plaza, atabales y chirimías, fuegos por la noche, y "seguianlos seys maquinas de fuego sobre seys carros, y entre carro, y carro cuatro Etiopes vestidos de la librea de los Ministriles, con montantes de fuego al hombro; que todo representaua vn alegre y vistoso aparato" (1671: fol. 101). Tras los carros, sin embargo, aparecen elementos propios de la fiesta religiosa, como la procesión (haciendo cinco estaciones) protagonizada por las cofradías de la ciudad, con sus estandartes, etc. Pero también las procesiones experimentaron, como es bien conocido, un proceso de transformación, o transculturación, al aclimatarse en territorio americano.

Y así vemos, en este texto, que en la procesión "discurrian varias danças de diversas representaciones de trajes, y estilos conforme a la vsança antigua de las muchas naciones de estos Indios: y iban repartidos a trechos varios ternos de dulces chirimias, que todo era pasmo de la admiracion, y mas que tierno incentiuo de la ternura" (1671: fol. 101). Concluye la fiesta con toros y cañas, “a que salió personalmente su excelencia”, nuevamente descrito en su "bizarria,

\footnotetext{
7 Otro sermón fundamental que también es una reivindicación criollista a partir de la religiosidad y de la alabanza a Santa Rosa de Lima es el de Juan de Espinosa y Medrano titulado "Oración Panegírica a la Gloriosa Santa Rosa”. Si el sermón de Meléndez fue pronunciado en Lima, este lo fue en Cuzco y se encuentra recogido en La novena maravilla nuevamente hallada en los panegíricos sagrados que en varias festividades dixo el Sr. Arcediano Dr. D. Juan de Espinosa Medrano, primer Canónigo magistral, Tesorero, Chantre y finalmente Arcediano de la Catedral del Cuzco en los reinos del Perú, Presentóles con fineza al Orden del Gran Patriarca, Santo Domingo, el Maestro Agustín Cortés de la Cruz. Capellán Real de la gran ciudad del Cuzco, discípulo del autor que los saca a luz y los imprime a su costa, Valladolid, 1695. Para un análisis del sermón, vid. Perilli 2011.
} 
ostentacion y aparato...” (1671: fol. 101-103). Finalmente, el autor cierra el volumen con la mencionada recopilación de poemas en honor a Santa Rosa.

Fijémonos a continuación en los elementos de reivindicación americanista, añadiendo nuevos detalles relevantes a los ya destacados en los artículos citados. En primer lugar, es llamativa la expresión de la queja del autor ante el hecho de la tardanza de la llegada de la noticia a Lima, por la cual fueron los últimos en festejarla: "La distancia grande, que ay de Lima a Roma, fue causa de que llegase a nosotros tan tarde la noticia de tan esperado bien, que ya la auian gozado, y celebrado estraños, quando aun no le sabiamos los propios, viniendo a ser los vltimos al aplauso, los que por naturaleza deberiamos de ser los primeros al culto” (1671: fol. 7). Nótese la utilización de la palabra "extraños" para referirse a los peninsulares y la molestia que ello produce en "los propios”, obvia expresión de ensalzamiento americanista situada al comienzo de la relación.

Resulta interesante añadir a esta expresión de contrariedad y queja, ya señalada por los críticos, otra no menos llamativa, que parte de una reflexión sobre el poder de la palabra para perpetuar los hechos históricos, y sobre el alto coste de la imprenta en Perú, “solo desgraciado en esto" (Meléndez 1671: fol. 22) (reparemos en que se aprovecha cualquier inciso para el enaltecimiento de lo propio). En este punto es importante la protesta expresada con respecto a las impresiones de libros americanos en España:

[...] y esta es la causa de que tantos sugetos grandes, que han ilustrado estos Reynos, en los pulpitos, y catedras, y de que oy estan pobladas las celdas de los Conuentos no tengan ya el mundo lleno de libros, sin que les aya valido a algunos emviar sus obras a España, donde se hazen de valde las imprentas, que como alla no ay a quien les duela, salen, con el descuydo del impresor, tan desfiguradas de los moldes, que no las conocerà el ingenio que las pario (Meléndez 1971: fol. 22).

A partir de estos reproches, tan significativos para observar el creciente distanciamiento de la colonia con respecto a la metrópoli, el texto insiste constantemente en llamar a Santa Rosa la "Paysana", 
emblema de la nación peruana, que es la de los dominicos criollos. Y en convertirla en símbolo del orgullo criollo al aparecer como “nuestra fragrante Peruana Rosa”, "nuestra ilustre criolla”, cuyos milagros son "admiracion del Mundo”.

\subsection{La exaltación de Lima en la tradición de las laudes civitatis}

Esta construcción de Santa Rosa como símbolo identitario se intensifica al aparecer rodeada, insistentemente, de elementos mitificadores tanto de la naturaleza del Perú como de la ciudad de Lima. Así, por ejemplo, cuando se alude al río Marañón, uno de los principales de América: "No hay que mendigar agenos Nilos, ni Eufrates, quando tenemos a este Rey de los rios en las Indias” (Meléndez 1671: fol. 19). Por su parte, la mitificación de la ciudad de Lima es eje vertebral de todo el texto y comienza en el Exordio: "Riquisimo Reino del Perú, y Nobilisima sobre muy leal Ciudad de Lima, opulento emporio suyo, que sin agrauio de otra lo pudiera ser del Mundo" (fol. 1). Un encomio superlativo del lugar elegido para ser patria de Rosa de forma que los elogios a Rosa lo son a la ciudad, se retroalimentan: "Por el abril de 1586 brotó a respirar fragrancias esta Rosa en el vergel florido desta Metropoli de la America”, que murió en 1617 (fol. 2). Los ejemplos son numerosos, desde los que fusionan la ciudad con la homenajeada en aras de esta mitificación mutua:

"la Beatificación de vna hija, las Primicias de este Reyno, la Primogenita de esta insigne, y nobilisima Ciudad de los Reyes, nunca mas gloriosamente coronada, que teniendo tal Hija por corona, sobre las tres, que la ciñen; de nuestra Criolla, digo, la Beata Rosa de Santa Maria” (fol. 37)

“mas gloriosa la demostración en su propia Patria la Ciudad de los Reyes, de donde es hija, y Patrona la Virgen Rosa ( jo dichosa Lima!)" (fol. 37)

pasando por los que utilizan el recurso clásico de las crónicas de Indias, esto es, la equiparación de Lima con ciudades míticas de la Antigüedad: “nueua Troya Lima feliz por su Rosa, mejor, que desdichada aquella por su Elena, se concedia toda por materia de 
vna continuada hoguera" (fol. 73); ejemplos en los que emerge el mito de las riquezas del Nuevo Mundo: "que la plata de que es dueño le hace verse seruido con lo mejor de todas las naciones” (fol. 27); o el encomio de la jerarquía eclesiástica: la misa se realizó “con la magestad que acostumbra esta gran Metropolitana”, y sobre el Arzobispo que la ofició: "lustre de la religion, honor de nuestro hemisferio, hijo de N. Prouincia” (fol. 78); la alusión a la tres veces coronada Ciudad de los Reyes: "a los pies de Rosa las tres coronas, blason de la Ilustre Patria” (fol. 84); o la identificación con espacios míticos de la antigüedad: "y desde las Riberas del Nilo, donde tuuo su origen la rosa natural [...] hasta las del Rio Lima, o Rimac, que este es su nombre, donde tuuo la mistica su principio, y fin” (fol. 91).

Diez años después, en la segunda parte de Tesoros verdaderos de las Indias, esta mitificación urbana se complementa con la comparación crucial, señalada por Mazzotti, entre Lima y Jerusalén, “y hasta fue diseñada por Dios, con lo cual se le otrogaba a la ciudad rango de punto simbólico fundamental dentro de un metarrelato providencialista sobre el orden cristiano en el Nuevo Mundo" (Mazzotti 2016: 157). Por este camino, en su capítulo de Lima fundida el crítico llega a la deducción última, que permite la identificación de Lima con el Paraíso Terrenal. Es más:

El diseño divino también conllevaba que el plan providencialista podría incluir la traslación del centro de la fe cristiana, recentrando así el paradigma europeo en relación con la superioridad de esa tercera parte del Viejo Mundo sobre las otras de la humanidad conocida. Lima, pues, se convertía en el axis mundi para la transmisión de la fe. Recordemos, por eso, que Meléndez no solo cuestiona la racionalidad ("indigna de figura humana”) de los peninsulares, sino que también formula un espacio renovado para el mejor desarrollo y prevalencia tanto de la pureza de sangre como de la más alta vida espiritual posible en su momento (Mazzotti 2016: 158).

Cabe añadir en este punto que incluso en la reivindicación de "la más alta vida espiritual” para Lima también habría disputas internas. En este sentido, Fernando Iwasaki, al recordar la "conciencia criolla" que surge en "los testimonios de los testigos 
que acudieron a declarar en la causa por la beatificación de Rosa de Santa María tras su muerte en 1617 (Hampe 1997 y 1998)” (2018: 111-112), opina: "Nada que objetar. Sencillamente pienso que no hay que descartar que las propias órdenes religiosas e incluso los mismos creyentes compitieran entre sí por la hegemonía del 'territorio devocional'” (2018: 112).

En cualquier caso, más allá de las disputas internas, esta línea de exaltación superlativa de la urbe que ya estaba en la Festiva pompa, y que inscribe estos textos en la tradición de las laudes civitatis que tanta relevancia tuvieron para la consolidación de los virreinatos y sus orígenes, permite crear el contexto idóneo para que los habitantes de Lima a su vez se incluyan, en el texto, en toda esta grandeza, para la cual se utiliza también el tópico de la fertilidad de la naturaleza asociado a Santa Rosa:

Si las plantas de vida vegetable, por la cercanía, por la vecindad, y por auer nacido dõde nació la Beata Rosa, dan gracias a Dios imitándola; con quanta mayor razón nos executa a nosotros viuientes racionales, que nacimos en la mesma Ciudad que ella nació , y tenemos la planta, no en el Parque de la Tierra, sino la Rosa fragante en los jardines del Cielo ya Beatificada, hermana nuestra tan cercana, y tan vezina, el dar a Dios continuas gracias (fol. 39).

En definitiva, la fusión entre Rosa, la ciudad y sus habitantes resulta en una operación mitificadora que obedece a un claro programa vindicativo, que tendrá como punto definitivo la abierta defensa criollista.

\subsection{Indígenas y criollos en el ideario de Meléndez}

Otra cuestión esencial para la construcción del programa ideológico criollo que se desarrolla en el texto es la que atañe a la participación indígena en los fastos, que aparece en estas líneas así descrita: "Ni en la miseria de los pobres Indios faltó agasajo que hazer a su divina Paysana [...] fabricaron a su triunfo hermosos triunfales arcos [...] de varias fragrantes dispuestos en lasos, que aunque a su barbaro modo, si eran gusto del olfato, seruian de diuersion apacible a los 
ojos" (Meléndez 1671: fol. 27). Si bien este fragmento ya ha sido señalado por los críticos para referirse a los modos con que la fiesta barroca y el texto que la sucede incluyeron al indígena en el espacio de las colonias, haciéndolo partícipe en la escena festiva, cabe añadir esta otra referencia sustancial del texto, significativa de la dimensión de dicha integración que, sin embargo, lo confina al espacio de lo ajeno, lo "otro" de la sociedad colonial: "porque no solo ay persona rica, o pobre, alta o baja que no le tenga en su casa con singular reuerencia, hasta el mas cuitado Indio" (fol. 150).

Y si el indio aparece de este modo en el texto, fundamental es también reparar en este párrafo en el que Juan Meléndez realiza una reflexión explícita no solo sobre los criollos, que protagonizan el texto, sino sobre la propia denominación "criollo" que la refrenda:

No fue necesaria esta preuencion cuydadosa a los que con viuos fuegos de feruorosos afectos, que encendio la deuocion celebrauan en sus almas los triunfos de su Criolla; pero fue atento cuydado de don Diego de Caruajal, Cauallero de la Orden de Calatraua, Correo mayor de las Indias, y de don Álvaro Namamuel de los Ríos, Cauallero del Orden de Alcantara, Alcaldes Ordinarios, y Criollos ambos de Lima, que bastan solos a honrar este nombre de Criollos, mal recebido de algunos, como si por si los nombres fuesen capaces de merito u de demerito (1671: fol. 72).

El párrafo es intensamente significativo en varios detalles: obviamente, el determinante posesivo para referirse a Santa Rosa como "su" criolla, pero sobre todo la reivindicación de la palabra criollo -frente a los intentos de desprestigiar a quienes la encarnabanapoyada en la defensa de la valía de las personas por sus actos, frente a los prejuicios de clase y/o raza; reivindicación que está en la base del erasmismo y que se desarrolla en los siglos de Oro en obras cumbre como el propio Quijote de Cervantes. Los términos en que se cifra esta reivindicación del vocablo criollo sellan la ubicación de la Festiva pompa en los albores de la "polémica del Nuevo Mundo" que, como he adelantado, tendrían un desarrollo mayor en Tesoros verdaderos de las Indias diez años después, tal y como explica 
Mazzotti en Lima fundida: “el uso del término 'criollo' resulta el arma inicial en la defensa de sus connacionales. Llega a oponerlos al carácter 'zafio' de muchos peninsulares” (2016: 156) ${ }^{8}$. Para ejemplificarlo, ofrece el crítico estas líneas de Tesoros que reproduzco por ser las más significativas en tanto que Meléndez radicaliza aquí la reivindicación, al punto de negar la humanidad a los peninsulares: "Para distinguirnos de los mismos españoles que nacieron en España, nos llamamos allà Criollos, voz que de cierto en España se ríen mucho: pero con la razón con que se ríen algunos de todo lo que no entienden: propiedad de gente zafia indigna de tener figura de hombres (I, f. 353r)" (citado en Mazzotti 2016: 155). Asimismo, añade otra cuestión esencial sobre este ideario de Meléndez, relativo a la limpieza de sangre, que se mantendría "mucho mejor en el Perú que en España”, según Meléndez (Mazzotti 2016: 156): "hacemos pues mucho aprecio los Criollos de las Yndias de ser Españoles, y de que nos llamen assi, y nos tengan por tales, y en orden a conservar esta sangre Española pura, y limpia se pone tanto cuidado, que no tiene ponderacion" (citado en Mazzotti 2016: 157). Con todo ello, el dominico sitúa a los criollos limeños en la cumbre social del imperio.

Por último, la evolución del texto, desde las quejas aludidas, pasando por la identificación de Santa Rosa con la ciudad de Lima y su tierra, y por la inclusión del indígena y la reflexión sobre el criollismo, conduce a un párrafo fundamental para completar el programa ideológico americanista; párrafo en el que surge la idea del mestizaje en la base del festejo: doce pelotones del ejército de "Indios, Pardos, y Morenos libres, gallardamente luzidos todos, siendo raros los que no cortaron nueua gala a su gusto para el dia, y ninguno el que dexo de traer, entre las plumas, rosa hechiza en

\footnotetext{
8 Explica Mazzotti la amplitud del término zafio en la época, no solo sinónimo de grosero o tosco, sino, en el castellano peruano, con el significado de desalmado (155). Y detalla que no se trataba de descalificar a todos los peninsulares, sino solo "a aquellos que no querían saber más de la sobrepujante superioridad —en términos criollos, naturalmente- de los reinos españoles al otro lado del Atlántico o los que, sabiendo de ella, no querían reconocerla” (2016: 156).
} 
el sombrero, comun gala que inuentó la deuocion, y aumentó su luzimiento, que sin duda hazen buen maridage rosa y plumas" (Meléndez 1671: fol. 29). Estos ejemplos de integración de elementos indígenas tienen varios momentos en el texto, como el de su aparición "conforme a la vsança antigua de las muchas naciones de estos Indios”. Y sin duda sirven para enaltecer la labor misionera de los dominicos y reclamar a Santa Rosa como miembro de la comunidad criolla, sin olvidar el vínculo con la comunidad indígena. Cabe señalar, por último, que esta imagen extraordinaria del maridaje de rosa y plumas, en un fasto de exaltación criollista, completa la confrontación entre el texto de Meléndez y las relaciones que narraron las fiestas que tuvieron lugar en España en honor de Santa Rosa, que se la apropian como figura peninsular.

\section{Conclusiones}

Recapitulando los aspectos centrales recorridos en el presente estudio, en primer lugar, hay que remachar que Festiva pompa es un texto especialmente significativo en el corpus textual de las relaciones de fiestas en el virreinato del Perú. Su gran riqueza en claves de interpretación socio-culturales y sus derivaciones geo-políticas no se agota en estas páginas, que pretenden llamar la atención sobre la necesidad de seguir explorando el texto desde otras perspectivas y con diferentes calas. En este sentido, hay que incidir en el hecho de que se trata de uno de los textos más extensos en lo que a relaciones de fiestas se refiere en el contexto peruano.

La perspectiva de análisis propuesta en el presente estudio permite constatar las operaciones culturales de intensificación del discurso criollista que, a las alturas del siglo XVII en que se produce el acontecimiento relatado — casi en las puertas del siglo "ilustrado"-, estaban solidificando la construcción identitaria en esa esfera de lo real que es el escenario festivo, redimensionado y eternizado en la relación que lo describe. Para ello, ha sido fundamental la contextualización del texto en el marco de la utilización de las relaciones de fiestas como discursos del poder y de propaganda deri- 
vados del propio acontecimiento social. Desde esta constatación, la relación de Meléndez, con su utilización de la figura de Santa Rosa como emblema para el alegato americanista frente a España, se erige en texto fundamental para el análisis de la evolución del criollismo a fines del siglo XVII y, siguiendo la argumentación de Mazzotti relativa a Tesoros verdaderos de las Indias, como otro antecedente de la disputa del Nuevo Mundo.

Asimismo, la comparación con las fiestas realizadas en ciudades españolas, en las que Santa Rosa ejemplifica el éxito dominicano en la empresa colonial o se configura como vasalla de la monarquía, es fundamental para comprobar la instrumentalización de su figura en la relación de Meléndez con el fin de convertir Lima en centro de la civilización y punto neurálgico de la cristiandad, espacio privilegiado en los límites del imperio. En esta línea, el texto permite seguir, asimismo, el programa ideológico que Meléndez desarrollaría una década después en Tesoros verdaderos de las Indias. Con todo ello, el análisis propuesto, centrado en el criollismo, ha permitido profundizar en algunos de los elementos del texto que lo configuran, fundamentalmente en los que atañen a la exaltación de la ciudad de Lima (siguiendo el tópico de las laudes civitatis) y de la sociedad criolla, con Santa Rosa como eje paradigmático en ambas direcciones.

Referencias bibliográficas

Fuentes primarias

ANÓNIMO

1669 Relación compendiosa y diaria de las fiestas que se celebraron por onze días en el Convento del Señor de Santo Domingo y el Rosario, de la ciudad de Cádiz, a la esclarecida y bienaventurada Rosa de Santa María, natural de Lima, en el Perú, del sagrado orden de Predicadores, en el día que se solemnize su Beatificación, que dio principio el día 14 de Enero, deste año de 1669. Cádiz. 
CAmpo de la Rinaga, Nicolás Matías

1668 Rasgo breve, disceño corto del religioso culto que la nobleza peruana consagró en el real convento de Santo Domingo de esta corte: a la bienaventurada Rosa de Santa María. Madrid: Mateo de Espinosa y Arteaga.

BOLÍBAR, Baltasar de

1668 Relación breve de las fiestas que el real convento de Santa Cruz de Granada dispuso y bizo en la beatificación de la venerable y Esclarecida Virgen la Bienaventurada Rosa de Santa María. Granada.

EsPinOSA y MEDRANO, Juan

1695 “Oración Panegírica a la Gloriosa Santa Rosa”. En La novena maravilla nuevamente ballada en los panegíricos sagrados que en varias festividades dixo el Sr. Arcediano Dr. D. Juan de Espinosa Medrano, primer Canónigo magistral, Tesorero, Chantre y finalmente Arcediano de la Catedral del Cuzco en los reinos del Perú, Presentóles con fineza al Orden del Gran Patriarca, Santo Domingo, el Maestro Agustín Cortés de la Cruz. Capellán Real de la gran ciudad del Cuzco, discípulo del autor que los saca a luz y los imprime a su costa. Valladolid.

León Pinelo, Diego de

1670 Celebridad y fiestas con que la insigne y nobilísima Ciudad de los Reyes solemnizó la beatificación de la bienaventurada Rosa de S. María, su patrona y de todos los reinos y provincias del Perú. Lima.

MeléndeZ, Juan

1671 Festiva pompa, culto religioso, veneración reverente, fiesta, aclamación y aplauso a la feliz beatificación de la bienaventurada Virgen Rosa de Santa María, tercera de la orden de predicadores, segunda Catalina Senense de la Iglesia, primera fragrante flor y fruto opimo desta plaga meridional, tesoro escondido en el Campo fértil desta muy noble, y muy leal ciudad de Lima. Lima.

1681 Tesoros verdaderos de las Indias en la Historia de la Gran Provincia de San Juan Bautista de el Perú de el Orden de Predicadores. Roma: Nicolás ángel Tisasio. 
Meneses y Arce, Gonzalo Andrés de

1670 Ilustración de la Rosa del Perú. Lima: Imprenta de don Juan de Quevedo.

Morales Pastrana, Antonio de

1671 Solemne, plavsible, festiva pompa. Magnifica, ostentosa celebridad, a la beatificacion de la gloriosa Rosa de Sta. María. Dedicala, al Ilmo. y Rmo. Sor. Maestro y Dor. D. Fr. Luys de Cifuentes Sotomayor, Obispo de Merida al Consejo de Su Magestad. México: Francisco Rodríguez Lupercio.

PARra, Fray Jacinto de

1670 Rosa laureada entre los santos. Epitalamios sacros de la corte, aclamaciones de España, aplausos de Roma, congratulaciones festivas del clero, y religiones, al feliz desposorio que celebro en la gloria con Christo la Beata Virgen Rosa de Santa María, de la Tercera Orden de Predicadores, patrona del Perú. Y beatificación solemne que promulgó en la iglesia militante la santidad de Clemente Nono. Madrid: Domingo Garcia Morras impresor del estado eclesiástico de la corona de Castilla.

\section{Fuentes secundarias}

Arias Cuba, Ibeth

2013 "En torno a las fiestas de beatificación de la Rosa indiana (1668-1671)". En Barroco iberoamericano: identidades culturales de un imperio. Vol II. Coords., Carmen López Calderón, María de los Ángeles Fernández Valle y María Inmaculada Rodríguez Moya. Santiago de Compostela: Andavira Editora, 581-592.

BÁEz Rivera, Emilio Ricardo

2012 Las palabras del silencio de Santa Rosa de Lima o la poesía visual del Inefable. Madrid: Universidad de Navarra / Editorial Iberoamericana.

Bonet Correa, Antonio

1983 "La fiesta barroca como práctica del poder". En El arte efímero en el mundo hispánico. México: Universidad Nacional Autónoma de México, 43-84. 
Cipolla, Carlo

1984 ¿Quién rompió las rejas de Montelupo? Barcelona: Muchnik editores.

DARNTON, Robert

1987 La gran matanza de gatos y otros episodios de la historia cultural francesa. México: Fondo de Cultura Económica.

FARRÉ, Judith

2012 "Poéticas del espacio en las relaciones de festejos novohispanos: la beatificación de Santa Rosa de Lima”. En Teorías poéticas en la literatura colonial. Ed., José Pascual Buxó. México: Universidad Nacional Autónoma de México, 283-301.

Ferrer Valls, Teresa

1993 Nobleza y espectáculo teatral (1535-1622). Valencia: UNED / Universidad de Sevilla / Universitat de València.

Folquer, Cynthia

2010 "Rosa de Lima (1586-1617): la libertad de ser mujer en el Perú colonial”. En La Orden de Predicadores en Iberoamérica en el siglo XVII. Ed., José Barrado Barquilla. Salamanca: Editorial San Esteban, 209-244.

Gerbi, Antonello

1960 La disputa del Nuevo Mundo: historia de una polémica (17501900). Trad., Antonio Alatorre. México: Fondo de Cultura Económica.

GinZBurg, Carlo

1981 El queso y los gusanos. Barcelona: Muchnik editores.

Hampe, Teodoro

1997 "Los testigos de Santa Rosa (una aproximación social a la identidad criolla en el Perú colonial)". Revista Complutense de bistoria de América. 23, 113-136. Madrid: Universidad Complutense.

1998 Santidad e identidad criolla: estudio del proceso de canonización de Santa Rosa de Lima. Cusco: Centro Bartolomé de las Casas.

IWASAKI, Fernando

2018 ¡Aplaca, Señor, tu ira! Lo maravilloso y lo imaginario en Lima colonial. México: Fondo de Cultura Económica. 
López Cantos, Ángel

1992 Juegos, fiestas y diversiones en la América española. Madrid: Editorial Mapfre.

LÓpez Estrada, Francisco

1982 "Fiestas y literatura en los Siglos de Oro: la Edad Media como asunto 'festivo' (el caso del 'Quijote')”. Bulletin Hispanique. 84, 293-294.

Maravall, José Antonio

1996 La cultura del Barroco. Barcelona: Ariel.

Mazzotti, José Antonio

2016 Lima fundida. Épica y nación criolla en el Perú. Madrid: Iberoamericana.

Millones, Luis

1993 Una partecita del Cielo. La vida de Santa Rosa de Lima narrada por Don Gonzalo de la Maza a quien ella llamaba padre. Lima: Editorial Horizonte.

Millar Carvacho, René

2003 "Rosa de Santa María (1586-1617): Génesis de su santidad y primera hagiografía”. Historia. 36, 255-273. Santiago de Chile: Pontificia Universidad Católica de Chile.

Mujica Pinilla, Ramón

2005 Rosa limensis. Mistica, politica e iconografía en torno a la patrona de América. México: Instituto Francés de Estudios Andinos / Fondo de Cultura Económica.

Paz, Octavio

1995 Sor Juana Inés de la Cruz o las trampas de la fe. México: Fondo de Cultura Económica.

Pérez, Mirzam C.

2015 "Fomentando la identidad institucional dominicana en tres relaciones de fiestas para la beatificación de Santa Rosa de Lima”. En Viajes y ciudades míticas. Eds., Álvaro Baraibar y Martina Vinatea Recoba. Pamplona: Servicio de Publicaciones de la Universidad de Navarra, 123-130. 
Perilli, Carmen

2011

“El Doctor Lunarejo y la Rosa Indiana. Criollismo y religión en un sermón barroco del siglo XVII". Cuadernos de CILHA. 12/15: 19-28.

Ramos Sosa, Rafael

1992 Arte festivo en Lima virreinal (siglos XVI-XVII). Sevilla: Junta de Andalucía / Asesoría Quinto centenario.

1997 "La fiesta barroca en Ciudad de México y Lima”. Historia. 30, 263-286.

Rodríguez, Dalmacio

1998 Texto y fiesta en la literatura novohispana (1650-1700). México: Universidad Nacional Autónoma de México.

VARgas Lugo, Elisa

1983 "Las fiestas de la beatificación de Santa Rosa de Lima”. En El arte efímero en el mundo bispánico. Ed., Marta Foncerrada de Molina et al. México: Universidad Nacional Autónoma de México, 87-105.

1998 "Iconografía de Santa Rosa de Lima en los virreinatos del Perú y de la Nueva España". En Simpatías y diferencias. Relaciones del arte mexicano con el de América Latina. México: Universidad Nacional Autónoma de México, 221-228.

Zugasti, Miguel

2013 "Santa Rosa de Lima, una santa del pueblo con sus fiestas y comedias para el pueblo". En Teatro español de los Siglos de Oro: dramaturgos, textos, escenarios, fiestas. Dir., José María Díez Borque. Eds., María Soledad Arredondo Sirodey, A. Martínez Pareira y Gerardo Fernández San Emeterio. Madrid: Visor, 117-151.

Recepción: 4/03/2019 Aceptación: 27/08/2019 